\title{
Contamination from polycyclic aromatic hydrocarbons (PAHs) in the soil of a botanic garden localized next to a former manufacturing gas plant in Palermo (Italy)
}

\author{
Santino Orecchio* \\ Department of Inorganic and Analytical Chemistry, University of Palermo, Viale delle Scienze, Building no. 17, 90128 Palermo, Italy
}

\section{A R T I C L E I N F O}

\section{Article history:}

Received 8 March 2010

Received in revised form 16 April 2010

Accepted 16 April 2010

Available online 24 April 2010

\section{Keywords:}

GCMS

Organic contaminants

Carcinogenic

Monitoring

\begin{abstract}
A B S T R A C T
The Botanical Garden lies within the city of Palermo, a few meters away from one of the largest unused Manufacturing Gas Plant in Sicily. The total concentrations of PAHs (23 compounds) in the soil of Botanical Garden ranged from 947 to $18,072 \mu \mathrm{g} / \mathrm{kg}$. The wide range of PAH concentrations (RSD = 84\%) found in the soil samples indicates heterogeneous levels of contamination in the area and this can be explained by considering the different tree distributions which prevents the homogeneous deposition of pollutants on the soil. Soils collected in the Botanical Garden generally showed the highest PAH concentrations, being almost 2-3 times higher than the concentration samples obtained in the urban reference sites and about 20 times higher than those in the rural stations. The total PAH concentrations, in the Botanical Garden soil resulted higher than the maximum concentrations allowed by the Italian legislation for the green areas. Perylene, was found in all the stations. From a careful study of the isomeric ratios, we can hypothesize that the soils of the Botanical Garden are mainly affected by localized MGP particulate deposition, suggesting that the partitioning between organic matter and PAHs is not the dominant process in the soils with higher organic matter content.
\end{abstract}

(c) 2010 Elsevier B.V. All rights reserved.

\section{Introduction}

Polycyclic aromatic hydrocarbons (PAHs) are formed by the incomplete combustion of organic material from both natural and anthropogenic processes such as volcanic eruption, coal pyrolysis and oil cracking. PAHs vary widely in molecular structure, usually ranging from 2 to 6 fused rings, and in several physical chemical properties such as water solubility which ranges from $31 \mathrm{mg} / \mathrm{L}$ for naphthalene ( 2 rings) to $290 \mathrm{ng} / \mathrm{L}$ for benzo[g,h,i]perylene ( 6 rings) [1].

PAHs are ubiquitous contaminants that have been released into the environment through industrial processes such as wood treatment facilities, household heating, road transport [2] and manufacturing gas plants (MGP) [3]. All these sources give off mixtures with quite different relative amounts of unsubstituted PAHs compared to their alkyl homologous [4]. Some authors [5] report that high temperatures yields soot devoid of alkyl PAH. Lower temperatures yields quite abundant substituted compounds, while extended periods of time at low temperatures yields PAH mixtures in which the alkyl compounds dominate (as in petroleum).

\footnotetext{
* Tel.: +390916451777.

E-mail address: orecchio@unipa.it.
}

Several PAHs have been classified by the International Agency for Researches on Cancer [6] as probable or possible human carcinogens $[7,8]$. Due to their high carcinogenic potency and their presence in the environment, benzo[a]pyrene is often used as indicator for human exposure to PAHs [9]. The US Environmental Protection Agency (EPA) [10] regulates sixteen PAHs as priority pollutants, seven of them being recognized as carcinogens. Certain PAHs are also classified as persistent organic pollutants (POPs) and persistent bioaccumulative chemicals [11].

Several decades ago, gas was produced worldwide from the pyrolysis of coal, coke, and oil at facilities that are termed Manufacturing Gas Plants (MGPs) (that are) commonly found in many countries, causing soil and groundwater contamination through improper disposal of coal tar and related waste products $[12,13]$. The primary organic pollutants of concern (that were) released into air, water and soil are PAHs [3].

Palermo Botanical Garden is both a botanic garden and a research and educational institution forming part of the Department of Botany of the University of Palermo. The garden lies within the city of Palermo, at a few meters away from one of the largest MGPs in Sicily (Italy) where coal, coke, and oil pyrolysis was used to produce gas from 1906 until 1988. Since 1988 the plant has been used to store and distribute natural gas.

In the present study, investigations on the soil of the Botanical Garden were carried out on the sixteen PAHs identified by the 


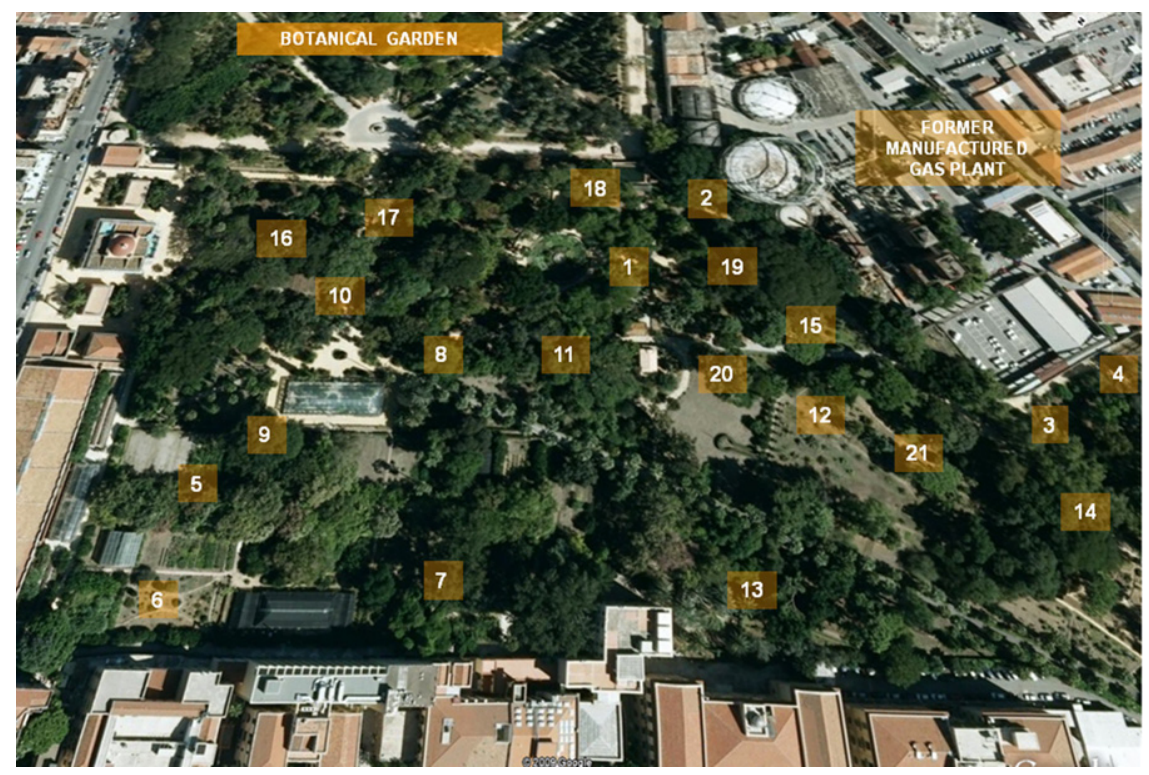

Fig. 1. Botanical Garden and sampling points.

US-EPA as requiring priority-monitoring action within the framework of environmental quality control [14]. Additionally, perylene and some methyl derivatives are included on the expanded scan of PAHs and alkyl PAHs recommended by NOAA (National Oceanic and Atmospheric Administration) [15] in order to obtain further information on the origins of the contaminants. Perylene is not universally considered a pyrogenic or a petrogenic PAH. Perylene is known to be one of the few PAHs found in nature. In sediments perylene can be formed from early diagenesis of plant pigments; it is sometimes considered a geochemical marker for plant pigments such as chlorophyll a, so its presence in environmental matrices is not necessarily indicative of anthropogenic contamination. Perylene is a marker of the terrestrial origin of organic matter in $e$ sediments [16-18].

Parent and alkyl-substituted PAHs provide some of the most definitive and ubiquitous tracers of organic matter in environmental systems $[5,18,19]$.

Soils are an important sink in pollution cycling [20]. However, they can also act as a contributors of persistent organic pollutants (POPs) for the atmosphere, especially the semi-volatile compounds in warm climates [21]. Usually, city soils show greater contamination than rural sites, due to their closeness to production sources [22]. A better understanding of soil contamination with PAHs helps to avoid hazards in food production and to restrict the deleterious effect of these contaminants on the soil and water ecosystems. Today, city soils in several places have been examined quite well with respect to their pollution status [12,23,24]. PAH fate in soils is also variable, ranging from biodegradable to recalcitrant. For example, some authors [25] reported a phenanthrene (3 rings) half-life in soil of 16-126 days while benzo[a]pyrene (five rings) ranges from 229 to over 1400 days.

In this work, together with PAHs, we analyzed water and organic contents because it has been demonstrated that the concentrations of PAHs in some environmental matrices were affected by the physiochemical properties of the samples such as organic matter and water content [26]. Generally, sediments with high water content $(40 \%=$ muddy $)$ are characterized by high values of PAHs, while sandy sediments (about 20\% water) report a low PAH content [27]. Environmental matrices with high organic content show high PAH concentrations [28].

Since there are no previous data on the PAH concentrations in the soils of the Botanic Garden an important goal of this investiga- tion is to establish whether the area is affected by environmental pollution and establish the background value for PAHs in order to compare the current results with eventual data obtained in future surveys. With the aim of finding the origin of PAHs in the soil of the Botanical Garden, we compared the distribution of single analytes in the investigated area with those of the reference areas and those of atmospheric particulate collected in Palermo (concentrations of single PAHs determined in this research on filters, aspiring a known volume of air in the various stations).

This paper reports a limited set of PAH ratios that exhibit the best potential in order to distinguish natural and anthropogenic sources.

\section{Materials and methods}

\subsection{Sampling and sites}

Palermo is a densely populated city (about 850,000 inhabitants) with a heavy load of vehicular traffic and with the major industrial activities within the city area. It is characterized by conspicuous air pollution [29-35]. The town is situated on the north-western coast of the island along the wide bay Piana di Palermo and is overlooked by Mt. Pellegrino ( $600 \mathrm{~m}$ above sea level). It is delimited on the NE by the Tyrrhenian Sea and it is surrounded by mountains 500-1000 $\mathrm{m}$ above sea level.

One of the largest Manufacturing Gas Plant (MGP) in Sicily is located in a green area inside Palermo bordering the Botanic Garden $\left(38^{\circ} 06^{\prime} 44^{\prime \prime} \mathrm{N}, 13^{\circ} 11^{\prime} 15^{\prime \prime} \mathrm{E}\right)$ (Fig. 1). The Botanical Garden covers about 30 acres of red soil that has evolved on a calcareous and tufaceous substratum. In the winter 2007, soil samples were collected in 26 sites of The Botanical Garden. In this area, the wind has an average annual speed of $5.4 \mathrm{~m} / \mathrm{s}$, with a minimum of $4.4 \mathrm{~m} / \mathrm{s}$ in July and a maximum of $6.4 \mathrm{~m} / \mathrm{s}$ in December. The prevailing wind directions are Ostro (from the south) between October and March, from the west in April, and Grecale (from Greece, east) between May and September.

The sampling sites were distributed as follows: 21 soil samples were collected in the Botanic Garden (Fig. 1) and 5 in urban zones about $2 \mathrm{~km}$ away from the influence area from the suspected contamination source. Triplicate samples were taken from the top $3 \mathrm{~cm}$ soil layer and kept in polyethylene bags. Once in the laboratory, 
Table 1

List of analytes, deuterated internal and surrogate standards (underlined), quantification confirmation ion for SIM GC-MS mode and quantification limits.

\begin{tabular}{|c|c|c|c|}
\hline Chemical & Quantification ions & Confirmation ions & Quantification limits ( $\mu \mathrm{g} / \mathrm{kg}$ d.w.) \\
\hline Acenaphthylene & 152 & 76,151 & 0.059 \\
\hline Acenaphthene & 154 & 152,76 & 0.090 \\
\hline Fluorene & 166 & 164,165 & 2.4 \\
\hline Acenaphthene $\mathrm{d}_{10}$ & 164 & & \\
\hline$\overline{\text { Phenanthrene }}$ & 178 & 188,89 & 3.9 \\
\hline 2 Methyl phenanthrene & 192 & 96 & 1.8 \\
\hline Anthracene & 178 & 188,89 & 0.28 \\
\hline Anthracene $\mathrm{d}_{10}$ & 188 & 188 & \\
\hline 2 Methyl anthracene & 192 & 96,82 & 0.28 \\
\hline 9 Methyl anthracene & 192 & 96,82 & 0.34 \\
\hline 2,4 Dimethyl phenanthrene & 206 & 89 & 3.7 \\
\hline 1,2 Dimethyl phenanthrene & 206 & 89 & 0.24 \\
\hline Fluoranthene & 202 & 101,200 & 3.1 \\
\hline Pyrene & 202 & 101,200 & 2.3 \\
\hline 1 Methyl pyrene & 216 & 108,94 & 0.28 \\
\hline Benz[a]anthracene & 228 & 114,226 & 1.2 \\
\hline Benz $[a]$ anthracene $d_{12}$ & 240 & 240 & \\
\hline Phenantrene $\mathrm{d}_{10}$ & 188 & & \\
\hline Chrysene & 228 & 114,226 & 3.3 \\
\hline Benzo $[b]$ fluoranthene & 252 & 126,250 & 2.8 \\
\hline Benzo $[k]$ fluoranthene & 252 & 126,250 & 1.4 \\
\hline Benzo[a]pyrene & 252 & 126,250 & 1.6 \\
\hline Crysene $d_{12}$ & 240 & & \\
\hline$\overline{\text { Perylene }}$ & 252 & 126,250 & 0.64 \\
\hline Indeno[ $1,2,3-c d]$ pyrene & 276 & 277,138 & 1.3 \\
\hline Dibenz $[a, h]$ anthracene & 278 & 279,139 & 1.3 \\
\hline Perylene $d_{12}$ & 264 & & \\
\hline
\end{tabular}

samples were protected with aluminum foils in order to prevent analytes adsorption from plastic. They were dried at room temperature until they reached a constant weight and sieved through a $2 \mathrm{~mm}$ mesh screen.

The repeatability of the sampling was preliminarily checked by analyzing for PAHs four different soil samples collected in different points of the same area $(3 \mathrm{~m} \times 3 \mathrm{~m})$. The sampling standard deviation (about 6\%) against the one from the analytical process resulted similar.

\subsection{Chemicals}

$\mathrm{N}$-hexane, cyclohexane and acetone analytical-reagent grade (Riedel-de-Haen, Milano, Italy) were used as solvents. A PAHs standard solution containing 16 PAHs compounds (concentration: 100-2000 mg/L) (Mixture SS EPA 610, Supelco, Milano, Italy) and perylene standard solution (Supelco, Milano, Italy) $(2000 \mathrm{mg} / \mathrm{L}$ ) were used. Solutions of PAH surrogates (anthracene $d_{10}$ and benz $\left[a\right.$ ]anthracene $\mathrm{d}_{12}$ ) and of internal standards (acenaphthene $d_{10}$, phenanthrene $d_{10}$, chrysene $d_{12}$ and perylene $d_{12}$ ) were supplied by Supelco, Milano. Solid methylated PAHs were supplied by Fluka (Milano, Italy).

\subsection{Atmospheric particulate sampling}

A total of 27 particulate samples was collected from October to December 2006, in three sampling stations belonging to the municipal air quality monitoring network (AMIA, Palermo), characterized by varying traffic density. The three selected stations were: an urban site, characterized by a traffic density lower than the other stations; a large square in the centre of town, exposed to a heavy traffic, made of cars and urban and extra-urban buses; an urban site, characterized by heavy traffic (flow), close to a crossroad with traffic lights and pedestrian crossings.

The samples were collected for several days drawing air for $24 \mathrm{~h}$ using a sampler (Explorer or mod. ZB1, Zambelli, Italy) equipped with a quartz fiber filter ( $47 \mathrm{~mm}$ in diameter, Ref. FQT, Albet). The fiber filters were weighed before and after sampling to determine the amounts of collected particulate. Before sampling, the quartz fiber filters were cleaned with dichloromethane and a mixture of $\mathrm{n}$ hexane/acetone $(50 / 50, \mathrm{v} / \mathrm{v})$ for $24 \mathrm{~h}$ each, and finally dried at $105^{\circ} \mathrm{C}$.

\subsection{Determination of water contents}

About $2 \mathrm{~g}$ of homogenized soil sample was dried at $180^{\circ} \mathrm{C}$ (the water may be linked to some salts (sulphates, etc.) requiring temperatures higher than $105^{\circ} \mathrm{C}$ ) for one night. The water content was determined by weight loss and was utilized to correlate all the results with the dry weight.

\subsection{Determination of organic matter contents}

Total organic matter in the soil was determined by ignition. Because this procedure is known to over-estimate the organic content due to the elimination of carbonates, we carried out the analysis on samples deprived of carbonates content. A dried sample aliquot (2-3g) was weighed in a platinum crucible and then carbonate was removed by treating the sample with $10 \%(\mathrm{v} / \mathrm{v}) \mathrm{HCl}$. Afterward the samples were dried at $60^{\circ} \mathrm{C}$ in an oven and the content of total organic carbon (TOC) of the soil was measured by determining the loss of weight after combustion at $550{ }^{\circ} \mathrm{C}$ for $4 \mathrm{~h}$.

\subsection{Quality control}

The analytical technique was preliminarily tested in order to identify the efficiency of the preparation and extraction procedure. The test was carried out by using samples without polycyclic aromatic compounds. These three "blank" samples were obtained through several extraction steps in $48 \mathrm{~h}$. After the complete PAH extraction was carried out (checked through GC-MS analysis), a known amount of PAH (EPA) standard mixture was added to each 'blank' sample. The test-samples obtained this way were extracted using the method chosen for the analyses of all the soils. The total PAH concentrations were calculated for the investigated compounds, and the recovery ranged from 70 to $102 \%$. The results 
Table 2

Concentration ( $\mu \mathrm{g} / \mathrm{kg}$ d.w.) of single polycyclic aromatic hydrocarbons (mean of three analysis) ${ }^{\mathrm{a}}$ in soil samples.

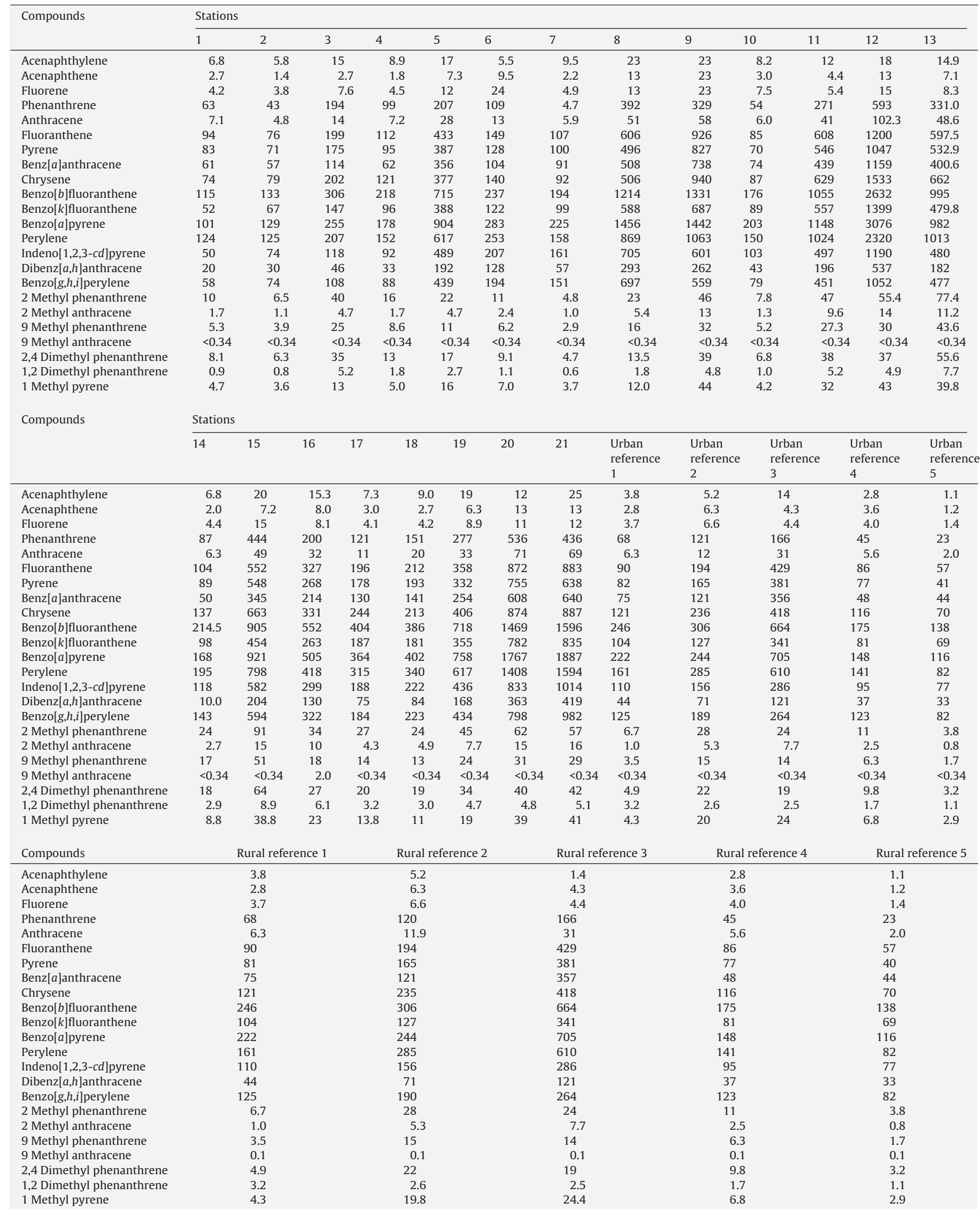

Concentration $(\mu \mathrm{g} / \mathrm{kg})$ of single polycyclic aromatic hydrocarbons in soil samples.

a Relative standard deviation of three analyses of PAHs ranged from $3 \%$ to $16 \%$. 


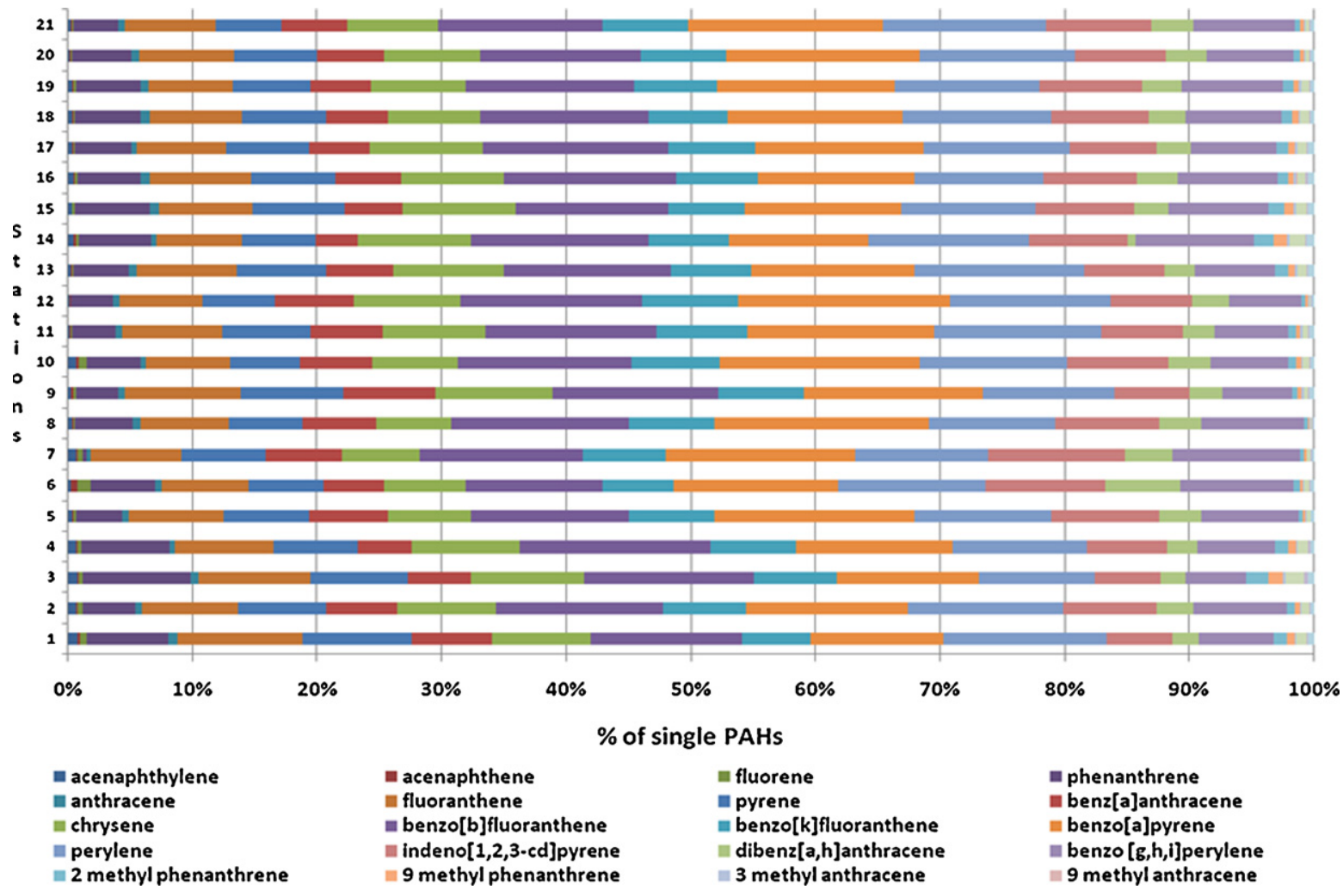

Fig. 2. Distribution of single compounds in soil samples.

showed that the Soxhlet method allowed a good PAH recovery with small standard deviations (with an average of $8 \%$ ).

The compound-specific coefficient of variation (as a measure of analytical precision) was within $4 \%$, based on 3 injections of the standard solution. A blank (cartridge without sample) was run up every 5 samples. All the reported data were blank corrected. Four deuterated PAH standards (acenaphthene $d_{10}$, phenanthrene $d_{10}$, chrysene $d_{12}$ and perylene $d_{12}$ ) were added as internal standard to each extract prior to the GC-MS measurements. Recoveries of the surrogate standards (anthracene- $\mathrm{d}_{10}$ and benz[a]anthracene- $\mathrm{d}_{12}$ ), added before the extraction procedure, were calculated. The results for the analyzed compounds ranged from 75 to $106 \%$. The calibration was performed once a week. Relative standard deviations of the three PAH analyses ranged from 7 to $16 \%$.

\subsection{Extraction and analysis}

All analytes were quantified through a Soxhlet extract of each soil sample. In brief, $3 \mathrm{~g}$ each of soil sample was mixed with $10 \mathrm{~g}$ of anhydrous sodium sulphate, spiked with a $250 \mu \mathrm{l}$ solution containing two surrogate PAHs (anthracene- $\mathrm{d}_{10}$ and benz $[a]$ anthracene- $\left.\mathrm{d}_{12}\right)$ and placed in pre-extracted Whatman extraction thimbles. The thimbles were placed into a $250 \mathrm{ml}$ Soxhlet unit and extracted after $24 \mathrm{~h}$ with a $250 \mathrm{ml}$ solution of hexane: acetone $(1: 1, v / v)$. Extracts were then reduced to near dryness on a rotary evaporator (Buchi R-124) $\left(T=35 \pm 0.5^{\circ} \mathrm{C}\right)$, take to $10 \mathrm{ml}$ and transferred into pre-washed and baked glass vials. The samples were then reduced to dryness under a gentle stream of $\mathrm{N}_{2}$ and then a $250 \mu \mathrm{L}$ solution containing four deuterated PAHs (acenaphthene $d_{10}$, phenanthrene $d_{10}$, chrysene $d_{12}$ and perylene $d_{12}$ ) was added to them.

One microliter of each sample extract was injected into a Shimadzu Gas Chromatograph (mod. GC-17A) fitted with a $30 \mathrm{~m}$ Equity-5 fused silica capillary column $(0.25 \mathrm{~mm} \times 0.25 \mu \mathrm{m}$ film thickness) and connected to a mass selective detector (GCMSQP5000) operating with a Shimadzu, CLASS 5000 acquisition data system. The carrier gas, helium, was maintained at a flow rate of $1.4 \mathrm{ml} / \mathrm{min}$ by electronic pneumatic control. The injection port temperature was $250^{\circ} \mathrm{C}$. The source temperature was $280^{\circ} \mathrm{C}$. The instrument was tuned on PFTBA. The oven program for standards and samples (soil and particulate) was as follows: $60^{\circ} \mathrm{C}$ for $2 \mathrm{~min}$, $14.5^{\circ} \mathrm{C} /$ min up to $325^{\circ} \mathrm{C}$ kept for $13 \mathrm{~min}$.

The mass spectrometer was operated in the selective ion monitoring mode (SIM) using separate molecular ions to identify and confirm compounds. Compounds, their respective ions and chosen internal standard are listed in Table 1.

An internal calibration curve, with five levels of concentration (standard solution containing 23 PAHs plus six deuterated standards) over the ranges $4-400 \mu \mathrm{g} / \mathrm{l}$ was used to set the response factors for each determined compound. The PAHs were analyzed and identified one by one, according to their retention and respective areas, relating them directly to the chosen internal standards (acenaphthene $d_{10}$, phenanthrene $d_{10}$, chrysene $d_{12}$ and perylene $\mathrm{d}_{12}$ ) added to the extracts.

Acenaphthene $d_{10}$ was chosen as internal standard for the quantification of acenaphthylene, acenaphthene and fluorene; phenanthrene $\mathrm{d}_{10}$ for phenanthrene, 2 methyl phenanthrene, anthracene, 2 methyl anthracene, 9 methyl anthracene, 2,4 dimethyl phenanthrene, 1,2 dimethyl phenanthrene, fluoranthene, pyrene, 1 methyl pyrene and benz[ $a$ ]anthracene; perylene $\mathrm{d}_{12}$ for chrysene, benzo[b]fluoranthene, benzo[ $k$ ]fluoranthene, benzo[a]pyrene chrysene $\mathrm{d}_{12}$ was chosen; for perylene, Indeno[1,2,3-cd]pyrene, dibenz $[a, h]$ anthracene.

After the final weighting, all the quartz filters used for PAH analysis of the particulate samples, were placed in ultrasound bath and extracted three times and for a 20 min period through cyclohexane $(8 \mathrm{ml})$. The extracts were filtered through $\mathrm{Na}_{2} \mathrm{SO}_{4}$, and concentrated in a rotary evaporator with thermostatic bath at $\left(T=35 \pm 0.5^{\circ} \mathrm{C}\right)$. 


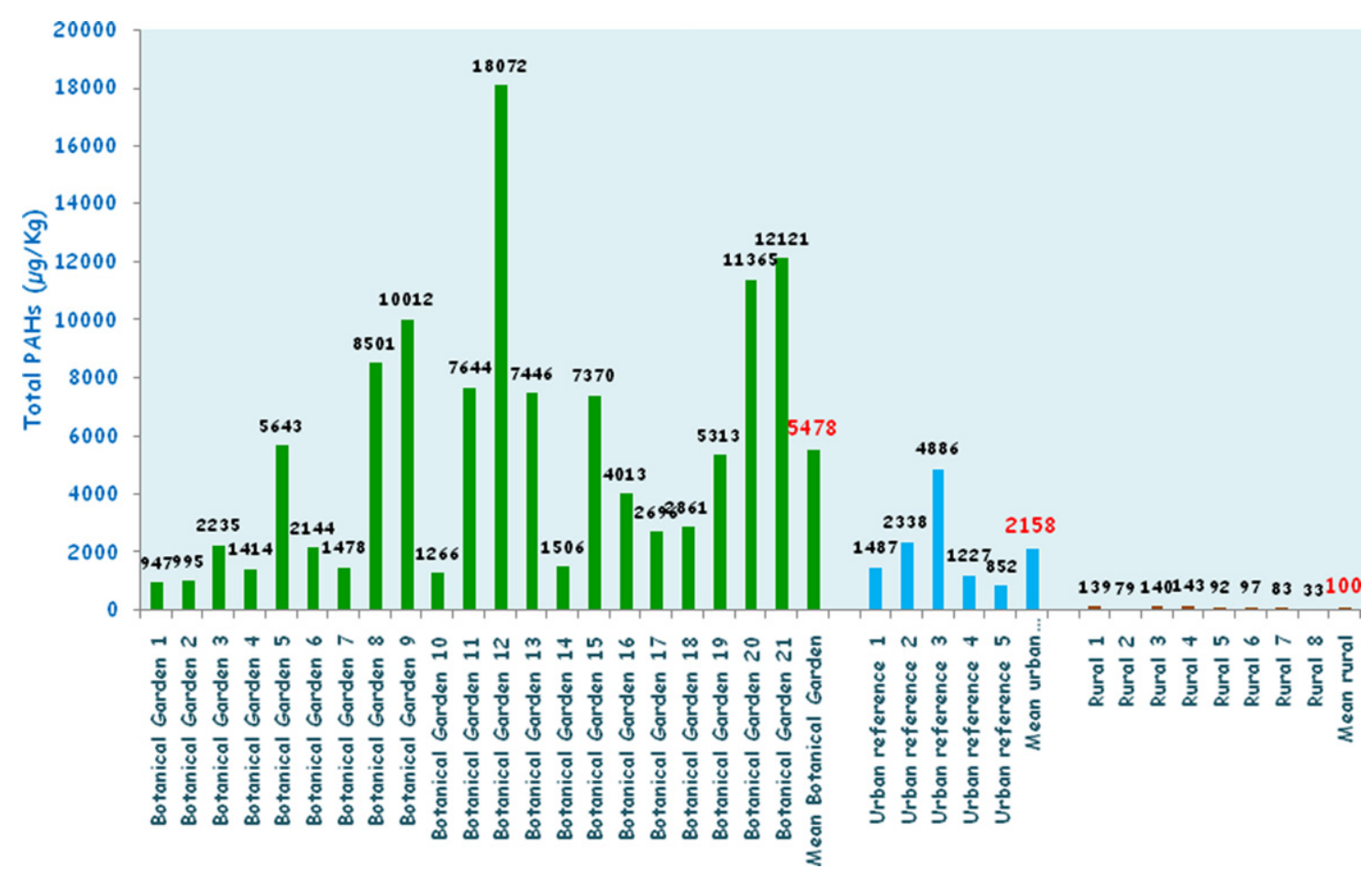

Fig. 3. Total PAHs concentrations (average of three analysis) in $\mu \mathrm{g} \mathrm{kg} \mathrm{d.w.} \mathrm{in} \mathrm{alnalyzed} \mathrm{soils.}$

The final volume was around $2 \mathrm{ml}$. The last stage of the procedure involved drying the PAHs solutions under a weak nitrogen flow at room temperature. The dry residue was dissolved in a $250 \mu \mathrm{L}$ solution containing the perdeuterated internal standards. All extracts were analyzed using GC-MS. Each sample was analyzed three times.

\section{Results and discussion}

The mean water content in 21 samples collected in the Botanic Garden was $4 \%$ and ranged from 1 to $8 \%$ while the mean content of organic matter was $11 \%$ and ranged from 6 to $15 \%$. The narrow range of water and organic contents (relative standard deviations were 46 and $23 \%$ respectively) found in the soil samples indicates homogeneous physical chemical properties in the investigated area.

The quantification limits for soil PAHs (Table 1), calculated on the basis of 10 blanks determinations as ten times the standard deviation of the blank tests, ranged from 0.059 to $3.9 \mu \mathrm{g} / \mathrm{kg} \mathrm{d.w.)}$.

In Table 2, we report the concentration of each individual PAH in the analyzed soils (The Botanical Garden, Urban and Rural references). The same type of distribution with 23 PAHs (expressed as a weight percentage) was observed in most of the sampling sites of Palermo Botanic Garden (Fig. 2).

The most abundant compounds in the Botanical Garden soil were benzo[ $a]$ pyrene, benzo[b]fluoranthene, perylene, chrysene, fluoranthene and pyrene which respectively constitute $15,14,12$, 8.0, 7.6 and $6.6 \%$ of the total PAHs.

The unsubstituted PAH, perylene, was founds in all the stations (Table 2). The most polluted station (no. 12) had the maximal absolute concentration $(2320 \mu \mathrm{g} / \mathrm{kg}$ d.w.) and was followed in decreasing order by stations nos. 21 and 20. However, on a relative basis, perylene in the samples collected in the Botanical Garden, ranged from 9.4 to $13 \%$ of the total PAHs.

Literature is discordant regarding the origins of perylene; some authors [36-38] argue that perylene can be produced in combustion processes of fossil fuels and biomass but marked abundance precludes its pyrogenic origin, in fact, a perylene contribution greater than $10 \%$ indicates a diagenic process. Significant evidences suggest that it can be produced biologically under anaerobic conditions [39-41]. Several authors reported PAH formation through plant and microbial metabolism [42] and showed that wood from forest contained naphthalene, phenanthrene and perylene. Thiele and Brummer [40] reported that bioformation of 3,4,5 and 6rings PAHs was observed after incubation of fresh plant and soil under reducing conditions. When only soil material was incubated, anaerobic biodegradation of three-ring PAHs was observed. Perylene quinones (pigments found in several insects, plants or fungi) are suspected to be degraded to perylene by anaerobic microbial metabolism [37]. Another theory postulates production via biosynthesis, independently of special precursors [43].

A perylene index, defined as the concentration of perylene divided by the total of 5 rings PAHs isomers, has been proposed to distinguish biogenic perylene from pyrogenic perylene [39]. Perylene indices greater than 0.1 often indicate the diagenetic (biogenic) inputs [39], whereas those $<0.1$ indicate pyrogenic origin of the compounds.

Regarding our results, perylene in the soil samples from the Botanical Garden shows high concentration and the relative indices were in the range of $0.20-0.30$ (mean value $=0.24 \pm 0.025, n=21$ ), far greater than 0.1 , suggesting that perylene in these samples originated mainly derives from its terrestrial biogenic precursors.

The presence of perylene in the soils of the Botanical Garden must not be related to vehicular traffic because this analita is found only in small concentrations in the atmospheric particulate collected in Palermo, in fact the perylene indices is in the range of 0.02-0.04 (mean value $=0.027 \pm 0.07, n=22$ ). This conclusion agrees well with the fact that perylene is not present or occurs only in small amounts among the products of combustion processes, probably due to its thermal instability or reactivity [37]. A correlation between the total $\mathrm{PAH}$ concentration and perylene content was calculated. The high value of $r(0.981)$ suggests that the perylene identified in the samples originates from the same type of emission that contains most of remaining PAHs. 
The total concentrations (the averages of three analyses) of 23 investigated compounds, expressed as the sum of the concentrations, $\sum$ PAHs, in the soil of Botanical Garden, ranged from 947 to $18,072 \mu \mathrm{g} / \mathrm{kg}$ of dry matrix (Fig. 3). The wide range of PAH concentrations (the relative standard deviation was $84 \%$ ) found in the soil samples indicates heterogeneous levels of contamination in the investigated area. This can be explained by considering the different distributions of vegetation (generally trees) on the area which prevents the deposition of pollutants on the soil.

The highest concentrations, up to $10,000 \mu \mathrm{g} / \mathrm{kg}$ of total PAHs were found in soils sampled very close to the border wall of the gas plant in sites nos. 12, 20 and 21.

A linear correlation between the total concentration of PAHs of the single stations and the distance from Gas Plant was calculated but it furnished no statistically significant results ( $r$ value was very low).

The soils collected in the Botanical Garden generally showed the highest concentrations, being the sum of the 23 PAHs almost 2-3 times higher than the one from the urban reference sites (5478 $\mu \mathrm{g} / \mathrm{kg}$ d.w. vs. $2157 \mu \mathrm{g} / \mathrm{kg}$ d.w. respectively) (Fig. 3) and about 50 times higher than that from rural stations $(101 \mu \mathrm{g} / \mathrm{kg} \mathrm{d.w.)}$ localized $30 \mathrm{~km}$ away from the Botanical Garden [44]. The Student $t$-test $(p<0.1)$, gave the total PAH concentrations measured in the Botanical Garden Stations $(n=21)$ higher than those in the urban sites $(n=5)$ and those in the rural sites $(n=8, p<0.05)$.

The higher Botanic Garden concentrations are likely to be influenced by generally greater proximity to PAHs sources (MGP), resulting in greater atmospheric emissions and subsequent deposition. It is well known that urban soils can have concentrations much greater than the rural locations, reflecting the broad relationship between PAH loading, population and industrial density.

It is estimated that background levels for soils without point sources or influence from traffic are less than $50-100 \mu \mathrm{g} / \mathrm{kg}$ [45]. Concentrations in tropical soils are in the range $12-380 \mu \mathrm{g} / \mathrm{kg}$ [46]. Some evidence [4] indicating that PAHs found in a rural soils, remote from major anthropogenic sources, cannot be attributed entirely to air pollution, but they seem to have an endogenous soil origin.

In the summary, the above results show that the area closer to the MGP is markedly affected by PAH contamination, being the levels in soil samples higher than those found in the reference sites. However, these concentrations are remarkably lower than most PAH levels found in a number of investigations from different
Table 3

Maximum concentrations allowed by the Italian legislation for villas, public gardens, green areas and commercial and industrial uses of soils (Gazzetta Ufficiale Repubblica Italiana no. 293 del 15-12-1999).

\begin{tabular}{lcc}
\hline Compounds & A & B \\
\hline Benz[a]anthracene & 0.5 & 10 \\
Benzo[a]pyrene & 0.1 & 10 \\
Benzo[b]fluoranthene & 0.5 & 10 \\
Benzo[k]fluoranthene & 0.5 & 10 \\
Benzo[g,h,i]perylene & 0.1 & 10 \\
Chrysene & 5 & 50 \\
Dibenzo[a]pyrene & 0.1 & 10 \\
Dibenz[a,h]anthracene & 0.1 & 10 \\
Indeno[1,2,3-cd]pyrene & 0.1 & 5 \\
Pyrene & 5 & 50 \\
Total PAHs & 10 & 100
\end{tabular}

A: Green area for public (mg/kg d.w.); B: area for commercial and/or industrial activities ( $\mathrm{mg} / \mathrm{kg}$ d.w.).

regions and countries. For instance, Jones et al. [47] determined the typical range of 14 PAHs in Welsh soils to be $108-54,500 \mu \mathrm{g} / \mathrm{kg}$.

The total PAH concentrations, in the Botanical Garden soil, result also higher than the maximum concentrations allowed by the Italian legislation (Table 3 ) for villas, public gardens and soils in green areas [48].

As shown in Table 2, the alkylated PAH concentrations in the soils of The Botanical Garden ranged from 0.8 to $5.5 \%$ of the total PAHs, with an average of $2.5 \%$, or from 18 to $270 \mu \mathrm{g} / \mathrm{kg}$ with an average of $112 \mu \mathrm{g} / \mathrm{kg}$. Specifically, the average percentage of the substituted PAHs, was similar to that in the reference samples (2.4\%). In general, alkyl-substituted PAHs may be both from natural sources (oil seeps, bitumen, coal, plant debris, forest and grassland fires) and anthropogenic sources (fossil fuels and combustion). The PAHs formed at high temperatures are dominated by unsubstituted species, while the lower temperatures of formation favors a higher degree of alkylation $[5,49]$. Thus, nonalkylated/alkylated indexes are high for pyrogenic PAHs mixtures and low in petrogenic PAHs. According to Prahl and Carpenter [50], the phenanthrene/methylphenanthrene $(\mathrm{P} / \mathrm{MP})$ ratio varies between 0.17 and 0.5 for petrogenic compounds and between 1 and 2 for combustion products. In the present study, this index ranged from 0.4 to 7.3. However, only one station (no. 7) show indexes $<1$. This may be due to the overlapping of other MP sources such as in situ diagenetic production [19] and plant detritus [50].

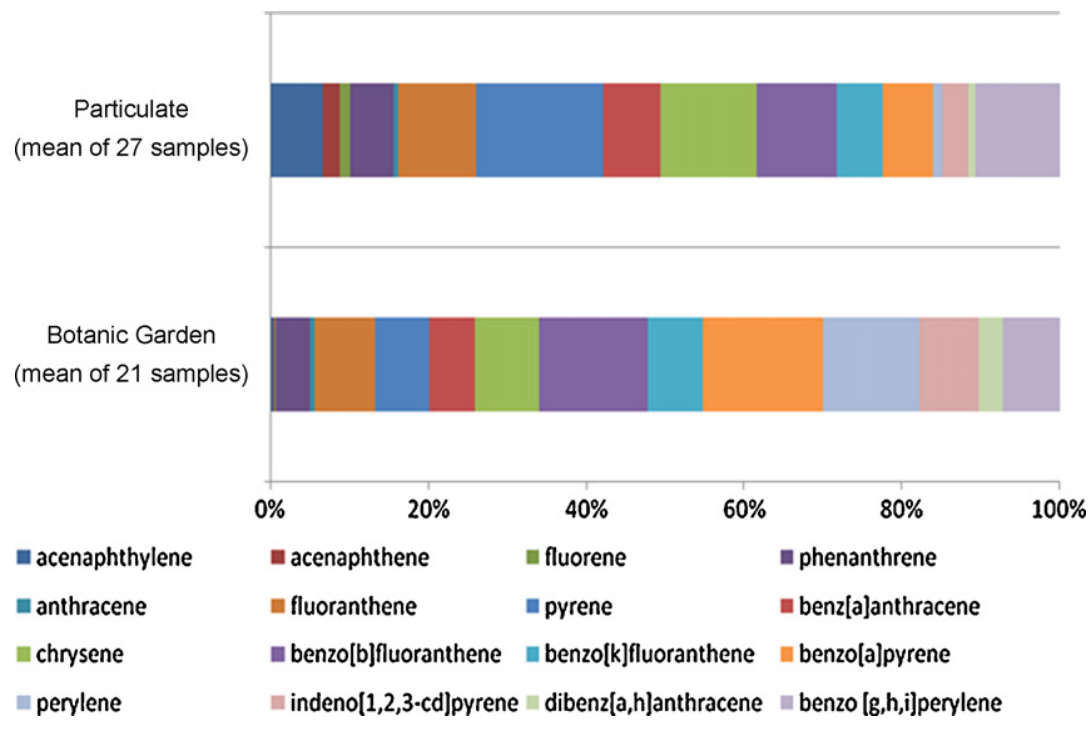

Fig. 4. Distribution of PAH in the soils and in the urban particulate. 


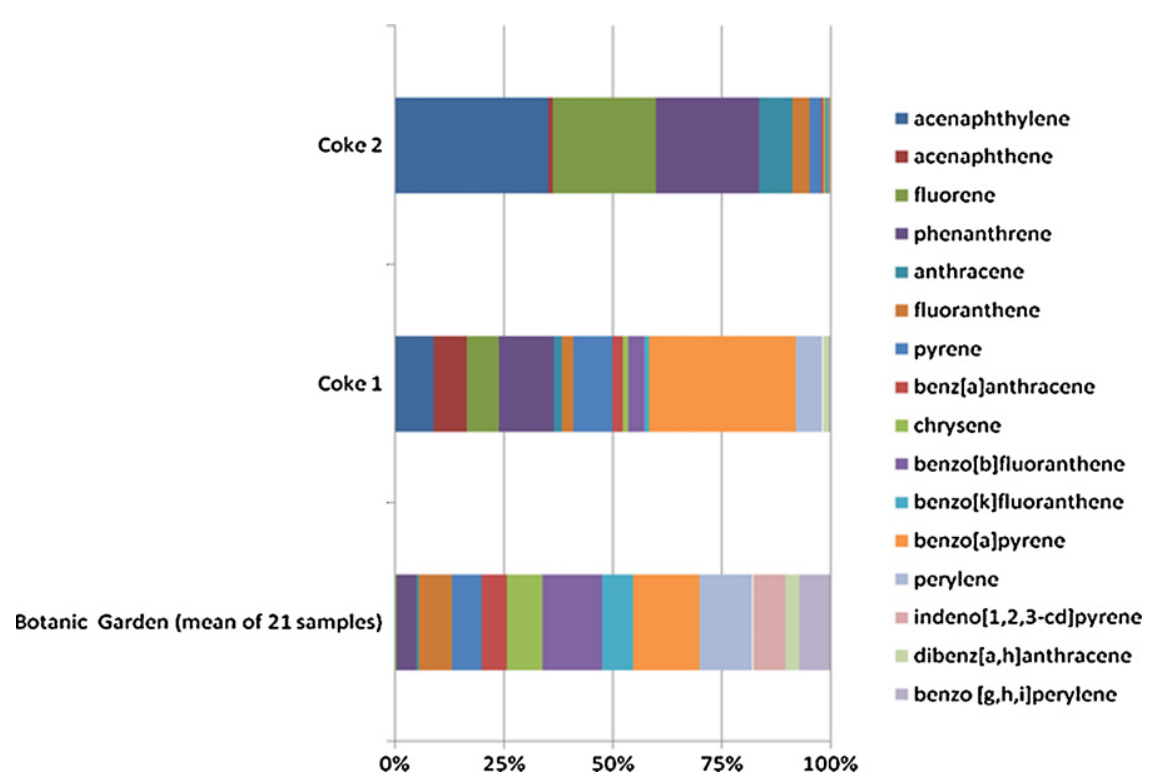

Fig. 5. Distribution $\mathrm{f}$ PASHs in two emission of coke combustion and in the Botanical Garden soil (mean of all samples).

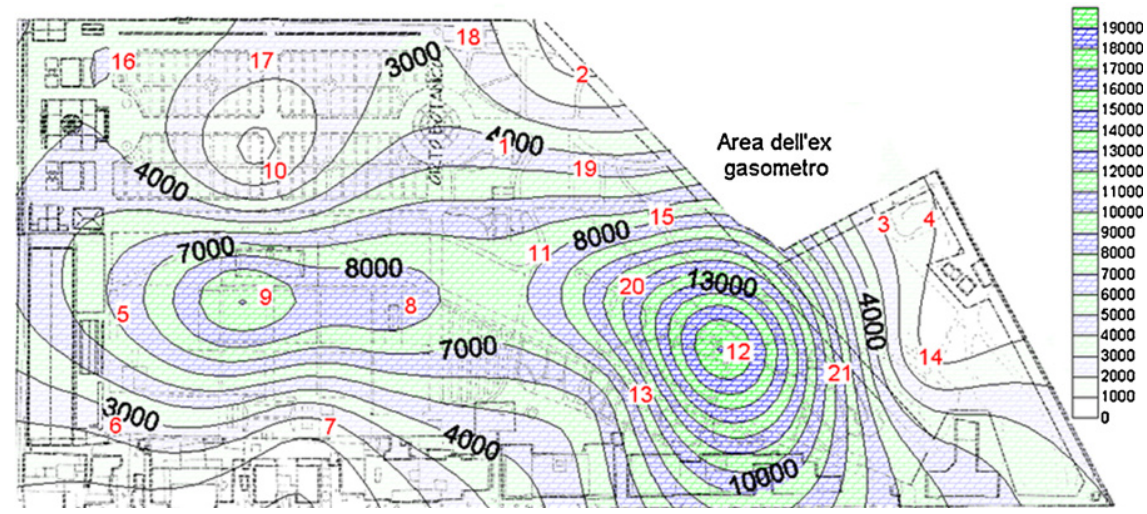

Fig. 6. Geographical distribution of total PAH in the area of Botanical Garden.

With the aim of finding a relationship between the distribution of single PAHs in the soils and that of the atmospheric particulate we compared (Fig. 4) the mean concentrations of the single PAHs, found in the filters aspiring a known volume of air in the various stations with those in the soils of The Botanical Garden.

The investigated soils (the Botanical Garden) showed a high amount of 4, 5 and 6-rings PAHs, whereas 3-ring PAHs were mainly present in the atmospheric particulate (about 20\%). The particu- late relative (percentage) concentrations of the volatile PAHs (AcPy, Acp, Fl, PA, An) were even higher than those in the soil samples.

On the other hand, according to their physical and chemical characteristics (low molecular weight, high vapor pressure, etc.), 3 rings PAHs are mainly in gaseous form [20] whose presence would be more related to long-range transport than to emissions from a local source. Combustion processes and in particular gas manufacturing have been pointed out as one of the most important sources

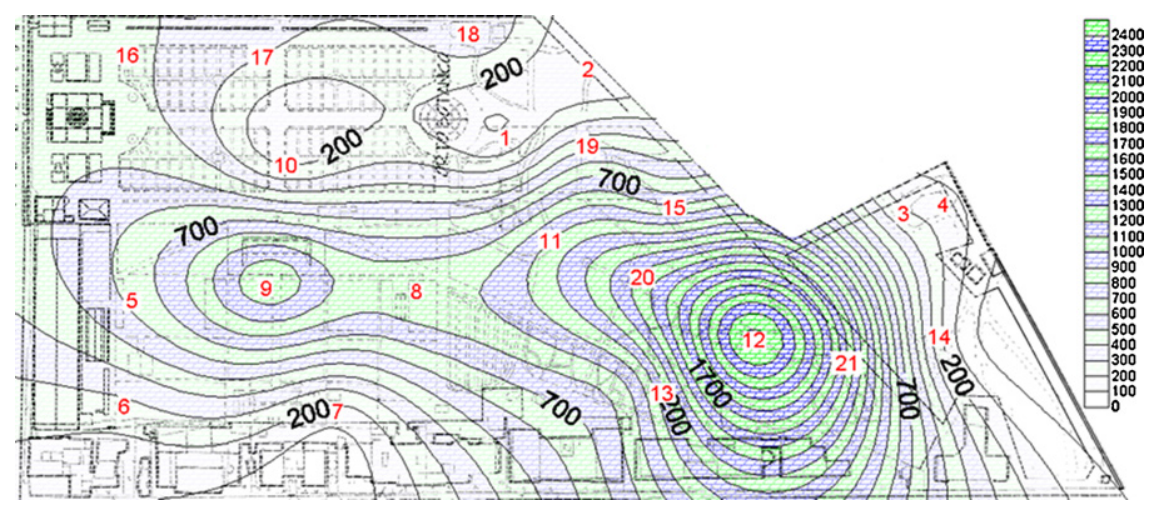

Fig. 7. Geographical distribution of perylene in the area of Botanical Garden. 


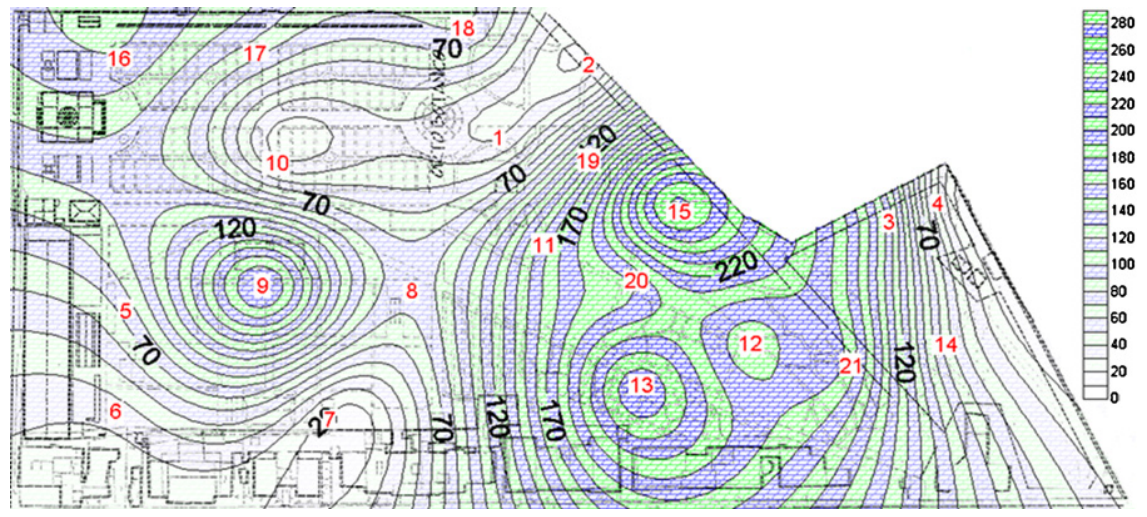

Fig. 8. Geographical distribution of methylated PAHs in the area of Botanical Garden.

of PAHs released into the atmosphere. 4, 5 and 6-ring PAHs are those with a higher molecular weight, and therefore, they would fall down more easily near their emission points [51] and in our case they accumulated in soil of the Botanic Garden. This has also been observed in studies investigating PAHs concentrations in soils near highways [52].

In order to assess specific inputs of PAHs in the soil of the Botanical Garden, the distribution patterns of PAHs was compared with those of two emissions deriving directly from coke combustion $[53,54]$. Fig. 5 shows that the PAHs distribution in the soils does not matches the distribution from coke combustion. Again, the investigated soils showed a high amount of high-ring PAHs whereas low-ring PAHs are mainly present in the considered coke emissions study.

A linear correlation between total PAH concentrations and single compounds content was calculated. The values of $r$ for the most representative compounds ranged from 0.71 to 0.99 . These results suggest that most of the PAHs identified in the soil samples originate from the same type of emissions.

In Figs. 6-8, the geographical distributions (obtained using Surfer 8) of the total PAHs, perylene and methylated PAH concentrations in the soil of The Botanical Garden can almost be compared and well reflects the position of the Gas Manufactured Plant, of the sampling points and of the vegetation density. This shows that the origins of considered analytes are the same. As can be seen from Fig. 1, site no. 12, located in a border area of the plant and in a zone not covered with high trees, shows the highest level of PAHs. In this site, in the past, we could frequently smell odors and observe stacks of gas emissions. Site nos. 5, 8, 9, 20 and 21 have intermediate levels of PAHs which are 2-5 times lower than site no. 12, implying that these stations were not greatly influenced by the plant. This result is presumably explained by considering the distance from the plant, the major wind direction and, in particular, the density of vegetation. In fact the mentioned sites define an almost perpendicular line to an axis drawn from the factory. Due to this proximity, the PAH flux was the same for each point, but the observed variations are probably related, as can be seen from Fig. 1, to the covering species and cultural practices.

The concentrations of total PAHs in the stations covered with trees (nos. 5, 8, 9, 11, 12, 15, 20,21) were statistically higher than those of the urban and rural sites (Student $t$-test at $p<0.05$ ).

The lowest levels of PAHs were detected in site nos. 4, 6, 7, 10 and 14 that are protected by a thick vegetation which absorbs contaminants and prevents their deposition on the ground.

The conclusion from the reported data was that PAH loadings in the Botanic Garden are strongly affected by the proximity to MGP, and most likely by enhanced atmospheric deposition. In other words, this implies that the soil burden is primarily a reflection of cumulative atmospheric deposition.

The water and organic matter content have been implicated as the key factors influencing PAHs content in urban and contaminated soils [54,55]. It is therefore appropriate to further explore the influence of these variables. Generally, analysis of the organic matter in environmental matrices (sediments, soils, etc.) show that concentrations of polycyclic aromatic compounds increase with an increment of the organic matter content. This trend has already been observed by a number of authors [56,57]. With the aim of identifying a relationship between the organic matter content and PAH concentrations determined in the investigated soils, we carried out a linear regression analysis. No statistically significant correlation was observed between water content and the concentrations of total PAHs. The total PAHs had only a weak positive correlation $(r=0.54)$ with organic matter content. From that, we can deduce that, in the investigated area, other factors, such as the proximity to sources, land use, wet deposition etc. clearly exert influences similar or stronger than the ones from the organic matter content on the concentration of these compounds, which exist in the atmosphere predominantly as particles [58].

Table 4

Ratios between isomer compounds and total index.

\begin{tabular}{|c|c|c|c|c|c|c|c|c|c|c|c|c|c|c|}
\hline Isomeric ratios/samples & 1 & 2 & 3 & 4 & 5 & 6 & 7 & 8 & 9 & 10 & 11 & 12 & 13 & 14 \\
\hline $\mathrm{fl} /(\mathrm{fl}+\mathrm{py})$ & 0.532 & 0.517 & 0.532 & 0.542 & 0.528 & 0.539 & 0.515 & 0.550 & 0.528 & 0.548 & 0.527 & 0.534 & 0.529 & 0.539 \\
\hline $\mathrm{An} /(\mathrm{An}+\mathrm{Phe})$ & 0.110 & 0.110 & 0.0688 & 0.0688 & 0.120 & 0.109 & 0.111 & 0.116 & 0.151 & 0.109 & 0.130 & 0.147 & 0.128 & 0.068 \\
\hline $\mathrm{B}[a] \mathrm{An} /(\mathrm{B}[a] \mathrm{An}+$ Cry $))$ & 0.452 & 0.419 & 0.360 & 0.338 & 0.486 & 0.426 & 0.497 & 0.501 & 0.440 & 0.460 & 0.411 & 0.430 & 0.377 & 0.268 \\
\hline Indpy $/($ Indpy $+\mathrm{B}[$ ghi $] \mathrm{Pe})$ & 0.464 & 0.500 & 0.522 & 0.511 & 0.527 & 0.516 & 0.517 & 0.503 & 0.518 & 0.564 & 0.524 & 0.531 & 0.502 & 0.453 \\
\hline Total index & 6.96 & 6.95 & 6.49 & 6.39 & 7.62 & 7.10 & 128 & 7.61 & 7.62 & 7.59 & 7.36 & 7.63 & 7.00 & 5.62 \\
\hline Isomeric ratios/samples & 15 & 16 & 17 & 18 & 19 & 20 & 21 & Ref.1 & Ref.2 & Ref.3 & Ref.4 & Ref.5 & Partic & \\
\hline $\mathrm{fl} /(\mathrm{fl}+\mathrm{py})$ & 0.502 & 0.550 & 0.524 & 0.524 & 0.519 & 0.536 & 0.581 & 0,533 & 0,544 & 0,533 & 0,543 & 0,588 & 0.388 & \\
\hline $\mathrm{An} /(\mathrm{An}+\mathrm{Phe})$ & 0.109 & 0.139 & 0.0844 & 0.118 & 0.106 & 0.117 & 0.137 & 0.0855 & 0.0900 & 0.166 & 0.111 & 0.0778 & 0.111 & \\
\hline $\mathrm{B}[a] \mathrm{An} /(\mathrm{B}[a] \mathrm{An}+$ Cry $))$ & 0.342 & 0.393 & 0.348 & 0.398 & 0.385 & 0.410 & 0.419 & 0.388 & 0.344 & 0.466 & 0.299 & 0.399 & 0.377 & \\
\hline Indpy/(Indpy + B [ghi]Pe $)$ & 0.495 & 0.481 & 0.505 & 0.499 & 0.501 & 0.511 & 0.508 & 0.477 & 0.455 & 0.522 & 0.444 & 0.488 & 0.244 & \\
\hline Total index & 6.48 & 7.15 & 6.49 & 7.00 & 6.89 & 7.13 & 7.56 & 6.41 & 6.20 & 7.81 & 6.17 & 6.69 & 5.13 & 1 \\
\hline
\end{tabular}


We can hypothesize that the soils of the Botanical Garden are mainly influenced by localized MGP deposition, suggesting that the partitioning between organic matter and PAHs is not a dominant process in the soils with high organic matter content.

Of all PAHs analyzed in this context some of them, especially the slightly volatile ones, are not regarded as carcinogenic. Within the remaining PAHs, there are substantial potency differences of potency in the size of several orders of magnitude. Because $\mathrm{B}[a] \mathrm{P}$ has been known to be the most carcinogenic compound. The carcinogenic potency of each collected sample was also determined in terms of its $\mathrm{B}[a] \mathrm{P}$ equivalent concentration $\left(\mathrm{B}[a] \mathrm{P}_{\mathrm{eq}}\right)$. The calculation of the $\mathrm{B}[a] \mathrm{P}_{\mathrm{eq}}$ for each individual $\mathrm{PAH}$ species requires the use of its toxic equivalent factor (TEF) relative to the $\mathrm{B}[a] \mathrm{P}$ carcinogenic potency for each given species. In the literature, only little data on TEFs is available [59,60]. In this study the list of the reported TEFs proposed by Nisbet and LaGoy was adopted, as this has been demonstrated to be a better reflection of the actual state of knowledge on the toxic potency of each individual PAH specimen relative to $\mathrm{B}[\mathrm{a}] \mathrm{P}[61]$. Concentrations of carcinogenic PAHs were calculated by

$$
\mathrm{TEQ}=\sum \mathrm{PAH} i \times \mathrm{TEF} i
$$

where TEQ is the toxic equivalent of the reference compound, $\mathrm{PAH} i$ is the concentration of PAH congener $i$, TEF $i$ is the toxic equivalent factor for PAHs congener $i$.

Concentrations of $\mathrm{B}[a] \mathrm{P}_{\mathrm{eq}}$ in the soil samples in The Botanical Garden ranged from 151 to $4291 \mu \mathrm{g} / \mathrm{kg}$, while in the reference sites they ranged from 184 to $1003 \mu \mathrm{g} / \mathrm{kg}$.

Differences in the total carcinogenic PAHs concentrations (referred to as benzo[a]pyrene) [47] among the stations were measured and the mean values are $33 \%$ both for the reference and for the Botanical Garden.

\subsection{Determination of PAH sources}

Sources of PAH pollution in the soil under investigation were confirmed by comparing some indexes calculated through concentration ratios of some polycyclic aromatic compounds. Phenanthrene/Anthracene ( $\mathrm{Ph} / \mathrm{An})$ and Fluoranthene/Pyrene (Fl/Py) ratios have commonly been used as a means to determine the main origins of PAHs $[18,62,63]$. Phenanthrene is thermodynamically more stable and its prevalence over anthracene supports petrogenesis for PAHs in soils. Indeed, petroleum usually exhibits a quite high Phen/Ant ratio. The values of isomeric ratios for the different samples of soil considered in the present paper are reported in Table 4.

The $\mathrm{An} /(\mathrm{An}+\mathrm{Ph})$ ratio for soils is greatly variable $(0.068-0.16)$, only three samples below report 0.10 . The highest average ratios are observed for the reference sample no. $3(0.16)$. The mean value for The Botanical Garden is 0.11, while the reference is 0.12 . Based on the 0.10 transition [64] $\mathrm{An} /(\mathrm{An}+\mathrm{Ph})$ ratios suggest combustion sources in the investigated area.

For the samples collected in The Botanical Garden, ratios $\mathrm{Fl} /(\mathrm{Fl}+\mathrm{Py})$ ranged from 0.50 to 0.58 . In agreement to the values of ratios $\mathrm{Fl} /(\mathrm{Fl}+\mathrm{Py})$ reported in literature [64] the PAHs in the investigated area can be considered of pyrolytic origin.

$\mathrm{BaA} /(\mathrm{BaA}+\mathrm{Chr})$ ranged from 0.26 to 0.50 with an average value of 0.41 . The literature data [64] suggest that $\mathrm{BaA} /(\mathrm{BaA}+\mathrm{Chr})$ ratios from 0.20 to 0.35 indicate either petroleum or combustion and $>0.35$ implies combustion. The analytical data indicate that PAHs found in most of the stations seem to mostly be of pyrolytic origin.

Accordingly to literature data [64], IP/(IP + BghiP) ratios of 0.20 most likely imply a petroleum origin, between 0.20 and 0.50 liquid fossil fuel combustion (vehicle and crude oil), and ratios $>0.50$ imply grass, wood and coal combustion. In our case, the ratios ranged from 0.44 to 0.56 .
In some cases, the values of four ratios are not in agreement with each others, and considering that, generally, the PAH sources in a matrix can be different and occasional, we calculated the total index [65] as the sum of single indexes (discussed before) respectively normalized for the limit value (low temperature sources-high temperature sources) reported in literature [64].

Total index $=\mathrm{Fl} /(\mathrm{Fl}+\mathrm{Py}) / 0.4+\mathrm{An} /(\mathrm{An}+\mathrm{Ph}) / 0.2+\mathrm{B}[\mathrm{a}] \mathrm{A} /(\mathrm{B}[a] \mathrm{A}+$ Chr $) / 0.1+\mathrm{IP} /(\mathrm{IP}+\mathrm{B}[$ ghi $] \mathrm{P}) / 0.5$.

When the total index is $>4$ we consider PAHs originating prevalently from high temperature processes (combustion) while lower values indicate prevalently low temperature sources (petroleum products). The results (Table 4 ) confirm that all the PAHs identified in the soil samples originate from combustion processes.

\section{Conclusions}

The present work can be summarized as follows:

1. The present study allowed optimizing the extraction and analytical conditions for the determination of PAHs in soils. Under these conditions, the recoveries are very good; in every case they are greater than $75 \%$ and in most of the cases near $100 \%$. The reproducibility is also satisfactory (relative standard deviation less than 16\%). The reproducibility and detection limits are also satisfactory, and the detection limits range from 0.059 to $3.9 \mu \mathrm{g} / \mathrm{kg}$ d.w.

The results reported here represent the first quantitative $\mathrm{PAH}$ investigations for The Botanical Garden area. Twenty-three PAHs were quantitatively analyzed in the soils of The Botanical Garden of Palermo near a former gas plant and we show their spatial distribution to consider the potential sources.

Concentrations of total PAHs in the soils of the Botanical Garden are 2-3 times higher than the reference stations and about 20 times than rural stations. This evidence shows that the entire area of The Botanical Garden is affected by the gas plant emissions of contaminants, which may represent a potential bioaccumulation hazard to the vegetation.

The larger presence of PAHs with high molecular weight was found in all samples and the values of isomeric ratios, as the PAH distribution indexes demonstrates that the majority of samples owe their origin to a predominant single cause i.e. anthropogenic combustion or pyrolysis processes, but a negligible quantity of PAHs can derive from biogenic sources because all samples contain traces of perylene.

The spatial patterns of the total, methylated PAHs and perilene confirm the identification of sources.

Total PAH content in nearly all samples are correlated with the concentrations of many of the single compounds. This evidence indicates that during the production process, in the gas plant a characteristic mixture of PAHs was produced and consequently for routine analyses only a (minor) smaller number of compounds could be analyzed.

The results of this study advice a continuous environmental monitoring of the chemical composition in the Botanical Garden soil.

Total PAH concentration shows a low positive correlation to the organic matter content.

A number of remediations options are available for the PAHs with lower molecular weight, but the inherent molecular recalcitrance and extreme hydrophobicity of the 5-6 ring constituents dramatically limit the success of the treatment technologies $[13,66,67]$. 


\section{Acknowledgement}

This study was funded by University of Palermo (MIUR ex 60\%).

\section{References}

[1] R.C. Sims, M.R. Overcash, Fate of polynuclear aromatic compounds (PNAs) in soil-plant systems, Res. Rev. (1983) 1-68.

[2] M. Howsam, K.C. Jones, Sources of PAHs in the Environment in: PAHs and Related Compounds: The Handbook of Environmental Chemistry-PAHs and Related Compounds, Chemistry, vol. 3-I, Springer, Berlin, 1998, pp. 137-174.

[3] S.B. Hawthorne, D.G. Poppendieck, C.B. Grabanski, C. Loehr, Comparing PAH availability from manufactured gas plant soils and sediments with chemical and biological tests. 1. PAH release during water desorption and supercritical carbon dioxide extraction, Environ. Sci. Technol. 36 (2002) 4795-4803.

[4] M. Blumer, W.W. Youngblood, Polycyclic aromatic hydrocarbons in soils and recent sediments, Science 188 (1975) 53-55.

[5] R.E. Laflamme, A. Ronald, The global distribution of polycyclic aromatic hydrocarbons in recent sediment, Geochim. Cosmochim. Acta 42 (1978) 289-303.

[6] IARC (International Agency of Research on Cancer), Overall Evaluation of Carcinogenicity: An Updating of IARC Monographs, vols. 1-42, Suppl. 7, Lyon, France, 1987

[7] IRAC, 2006, http://monographs.iarc.fr

[8] L.H. Keith, W.A. Telliard, Priority pollutants. A perspective review, Environ. Sci. Technol. 13 (1979) 416-423.

[9] R. Brown, A. Mittelman, Evaluation of Existing Methods to Rank the Relative Carcinogenicity of Polycyclic Aromatic Compounds (PAHs), Draft. Technical Resources, Inc., Contract No. 68-01-0022, for Office of Emergency and Remedial Response, Office of Solid Waste and Emergency Response, US Environmental Protection Agency, 1993

[10] F. Sun, D. Littlejohn, M.D. Gibson, Ultrasonication extraction and solid phase extraction clean-up for determination of US EPA 16 priority pollutant polycyclic aromatic hydrocarbons in soils by reversed-phase liquid chromatography with ultraviolet absorption detection, Anal. Chim. Acta 364 (1998) 1-11.

[11] L. Ritter, K.R. Solomon, J. Forget, M. Stemeroff, C. O'Leary, Persistent organic pollutants. Prepared for the International Programme on Chemical Safety (IPCS) within the framework of the Inter-Organization Programme for the Sound Management of Chemicals (IOMC), in: United Nations Environment Program, 1995.

[12] F. Haeseler, D. Blanchet, V. Ruelle, P. Werner, J.P. Vandecasteele, Ecotoxicological assessment of soils of former manufactured gas plant sites: bioremediation potential and pollutant mobility, Environ. Sci. Technol. 33 (1999) 4379-4384.

[13] B.W. Bogan, V. Trbovic, R. Paterek, Inclusion of vegetable oils in Fentons chemistry for remediation of PAH-contaminated soils, Chemosphere 50 (2003) $15-21$.

[14] B.R.T. Simoneit, Biomarker PAHs in the Environment, The Handbook of Environmental Chemistry-PAH and Related Compounds, vol. 3-I, Springer, Berlin, 1998, pp. 175-222.

15] R.J. Irwin, M.V. Mouwerik, S.Stevens, M.D. Seese, W. Basham, Environmental Contaminants Encyclopedia-PAHs Entry, National Parks Service Report, Water Resources Division, 1997. Environmental Contaminants Encyclopedia. National Park Service, Water Resources Division, Fort Collins, Colorado. Distributed within the Federal Government as an Electronic Document (Projected public availability on the internet or NTIS), 1998.

[16] S.N. Sporstøl, R.G. Lichtenhaler, K.O.K. Urdal, F. Oreld, J. Skei, Source identification of aromatic hydrocarbons in sediments using GC/MS, Environ. Sci. Technol. 17 (1983) 282-286.

[17] J.C. Colombo, E. Pelletier, C. Brochu, M. Khalil, J.A. Catoggio, Determination of hydrocarbon sources using n-alkanes and polycyclic aromatic distribution indexes. Case study: Rio de la Plata, Argentina, Environ. Sci. Technol. 23 (1989) 888-894.

[18] H. Budzinski, I. Jones, J. Bellocq, C. Pierrad, P. Garrigues, Evaluation of sediment contamination by polycyclic aromatic hydrocarbons in the Gironde estuary, Mar. Chem. 58 (1997) 85-97.

[19] S.G. Wakeham, C. Schaffner, W. Giger, Polycyclic aromatic hydrocarbons in recent lake sediments. I. Compounds having anthropogenic origins, Geochim. Cosmochim. Acta 44 (1980) 403-413.

[20] D. Mackay, D. Callcott, Partitioning and physical chemical properties of PAHs, in: The Handbook of Environmental Chemistry-PAHs and Related Compounds, vol. 3-I, Springer, Berlin, 1998, pp. 325-346.

[21] A.J. Sweetman, M. Dalla Valle, K. Prevedouros, K.C. Jones, The role of soil organic carbon in the global cycling of persistent organic pollutants(POPs): interpreting and modelling field data, Chemosphere 60 (2005) 959-972.

[22] N.Y.M.J. Omar, M. Ketuly, B.A.K.A. Radzi, N.M. Tahir, Concentrations of PAHs in atmospheric particles (PM-10) and roadside soil particles collected in Kuala Lumpur, Malaysia, Atmos. Environ. 36 (2002) 247-254.

[23] Z. Wang, J. Chen, X. Qiao, P. Yang, F. Tian, H. Li, Distribution and sources of polycyclic aromatic hydrocarbons from urban to rural soils: a case study in Dalian, China, Chemosphere 68 (2007) 965-971.

[24] J.J. Nam, O. Thomas Gareth, F.M. Jaward, E. Steinnes, O. Gustafsson, K.C. Jones, PAHs in background soils from Western Europe: influence of atmospheric deposition and soil organic matter, Chemosphere 70 (2008) 1596-1602.

[25] K.L. Shuttleworth, C.E. Cerniglia, Environmental aspects of PAH biodegradation, Appl. Biochem. Biotechnol. 54 (1995) 291-302.
[26] G.B. Kim, K.A. Maruja, R.F. Lee, J.H. Lee, C.H. Koh, S.S. Tanabe, Distribution and sources of polycyclic aromatic hydrocarbons in sediments from Kyeonggi Bay, Korea, Mar. Pollut. Bull. 28 (1999) 166-169.

[27] K.T. Benlanchen, A. Chaoui, H. Budzinski, J. Bellocq, P. Garrigues, Distribution and sources of polycyclic aromatic hydrocarbons in some Mediterranean coastal sediments, Mar. Pollut. Bull. 34 (1997) 298-305.

[28] G. Witt, Polycyclic aromatic hydrocarbons in water and sediments of the Baltic Sea, Mar. Pollut. Bull. 31 (1995) 237-248.

[29] A. Macaluso, M.R. Melati, S. Orecchio, The use of Olea europaea L. as passive samplers for polycyclic aromatic hydrocarbons Assessment Quality Air Palermo, Ann. Chim. 90 (2000) 83-90.

[30] M. Lombardo, M.R. Melati, S. Orecchio, Assessment of the quality of the air in the city of Palermo through chemical and cell analyses on Pinus needles, Atmos. Environ. 35 (2001) 6435-6445.

[31] L. Culotta, M.R. Melati, S. Orecchio, The use of leaves of Rosmarinus officinalis L. as samplers for polycyclic aromatic hydrocarbons assessment of air quality in the area of Palermo, Ann. Chim. 92 (2002) 837-845.

[32] AMIA, Il rilevamento acustico ed atmosferico nel Comune di Palermo, 4a relazione 2001-2002, Italy, 2003.

[33] L. Culotta, A. Gianguzza, S. Orecchio, Leaves of Nerium oleander L. as bioaccumulators of polycyclic aromatic hydrocarbons (PAH) in the air of Palermo (Italy) Extraction. GC-MS Analysis, Distribution. Sources, Polycyclic Aromat. Compds. 25 (2005) 327-344.

[34] S. Orecchio, PAHs associated with the leaves of Quercus ilex L.: extraction, GC-MS analysis, distribution and sources assessment of air quality in the Palermo (Italy) area, Atmos. Environ. 41 (2007) 8669-8680.

[35] G. Dongarrà, E. Manno, D. Varrica, M. Vultaggio, Mass levels, crustal component and trace elements in $\mathrm{PM}_{10}$ in Palermo, Italy, Atmos. Environ. 47 (2007) 7977-7986.

[36] M.J. Tissier, A. Saliot, in: Advances in Organic Geochemistry, John Wiley \& Sons, New York, 1983, pp. 268-278.

[37] C. Jiang, R. Alexander, R. Kagi, A. Murray, Origin of perylene in ancient sediments and its geological significance, Org. Geochem. 31 (2000) 1545-1559.

[38] H.H. Soclo, E.M. Garrigues, Origin of polycyclic aromatic hydrocarbons (PAHs) in coastal marine sediments: case studies in Cotonou (Benin) and Aquitaine (France) areas, Mar. Pollut. Bull. 40 (2000) 387-396.

[39] M. Venkatesan, Occurrence and possible sources of perylene in marine sediments-a review, Mar. Chem. 25 (1988) 1-27.

[40] S. Thiele, G. Brummer, Bioformation of polycyclic aromatic hydrocarbons in soil under oxygen deficient conditions, Soil Biol. Biochem. 34 (2002) 733-735.

[41] A. Giacalone, A. Gianguzza, M.R. Mannino, S. Orecchio, D. Piazzese, Polycyclic aromatic hydrocarbons in sediments of marine coastal lagoons in Messina, Italy: extraction and GC/MS analysis, distribution and sources, Polycyclic Arom. Compd. 24 (2004) 135-149.

[42] W. Wilcke, Polycyclic aromatic hydrocarbons (PAHs) in soil-a review, J. Soil Sci. Plant Nutr. 163 (2000) 229-248.

[43] W. Wilcke, M. Krauss, W. Amelung, Carbon isotope signature of polycyclic aromatic hydrocarbons (PAHs): evidence for different sources in tropical and temperate environments, Environ. Sci. Technol. 36 (2002) 3530-3535.

[44] S. Orecchio, Assessment of polycyclic aromatic hydrocarbons (PAHs) in soil of a Natural Reserve (Isola delle Femmine) (Italy) located in front of a plant for the production of cement, Hazard. Mater., 173, 15 1-3 (2010) 358-368.

[45] WHO/IPCS, Concise International Chemical Assessment Document 62: Coal Ta Creosote. Internationall Program on Chemical Safety, United Nations Environmental Program, World Health Organization, Geneva, 2004.

[46] W. Wilcke, S. Muller, N. Kanchanakool, C. Niamskul, W. Zech, Polycyclic aromatic hydrocarbons in hydromorphic soils of the tropical metropolis Bangkok Geoderma 91 (1999) 297-309.

[47] K.C. Jones, J.A. Stratford, K.S. Waterhouse, E.T. Furlong, W. Glger, R.A. Hites, C. Schaffner, A.E. Johnstonii, Increases in the polynuclear aromatic hydrocarbon content of an agricultural soil over the last century, Environ. Sci. Technol. 23 (1989) 95-101.

[48] Official Journal of the Italian Republic no. 293, 15-12-1999 (Ordinary Supplement no. 218) Law DM 471/99, Regulation no. 22.

[49] W.W. Youngblood, M. Blumer, Polycyclic aromatic hydrocarbons in the environment: homologous series in soils and recent sediments, Geochim. Cosmochim. Acta 39 (1975) 1303-1314.

[50] F.G. Prahl, R. Carpenter, The role of zooplankton fecal pellets in the sedimentation of polycyclic aromatic hydrocarbons in Dabob Bay, Washington, Geochim. Cosmochim. Acta 43 (1979) 1959-1972.

[51] A.A. Meharg, J. Wright, H. Dyke, D. Osborn, Polycyclic aromatic hydrocarbon $(\mathrm{PAH})$ dispersion and deposition to vegetation and soil following a large scale chemical fire, Environ. Pollut. 99 (1998) 29-36.

[52] J. Tuhackova, T. CajthamL, C. Novak, C. Novotny, J. Mertelik, V. Sasek, Hydrocarbon deposition and soil microflora as affected by highway traffic, Environ. Pollut. 113 (2001) 255-262.

[53] N.R. Khalilli, P.A. Scheff, T.M. Holsen, PAH source fingerprints for coke ovens, diesel and gasoline engines, highway tunnels, and wood combustion emissions, Atmos. Environ. 29 (1995) 533-542.

[54] W.L. Huang, P.A. Ping, Z.Q. Yu, H.M. Fu, Effects of organic matter heterogeneity on sorption and desorption of organic contaminants by soils and sediments, Appl. Geochem. 18 (2003) 955-972.

[55] C. Rumpela, M. Alexisa, A. Chabbi, V. Chaplot, D.P. Rassea, C. Valentin, A. Mariotti, Black carbon contribution to soil organic matter composition in tropical sloping land under slash and burn agriculture, Geoderma 130 (2006) 35-46. 
[56] J.M. Neff, Polycyclic Aromatic Hydrocarbons in the Aquatic Environment: Sources, Fates and Biological Effects, Applied Science Publ., London, 1979.

[57] H. Budzinski, M. Letellier, P. Garrigues, K. Le Menach, Optimisation of the microwave-assisted extraction in open cell of polycyclic aromatic hydrocarbons from soils and sediments. Study of moisture effect, Chromatographia 837 (1999) 187-200.

[58] R. Lohmann, G.L. Northcott, K.C. Jones, Assessing the contribution of diffuse domestic burning as a source of PCDD/Fs, PCBs, and PAHs to the UK atmosphere, Environ. Sci. Technol. 34 (2000) 2892-2899.

[59] M. Chu, C. Chen, Evaluation and estimation of potential carcinogenic risks of polynuclear aromatic hydrocarbons, in: Paper Presented at the Symposium on Polycyclic Aromatic Hydrocarbons in the Workplace, Pacific Rim Risk Conference, Honolulu, 1994.

[60] C. Nisbet, P. LaGoy, Toxic equivalency factors (TEFs) for polycyclic aromatic hydrocarbons (PAHs), Regul. Toxicol. Pharmacol. 16 (1992) 290-300.

[61] T. Petry, P. Schmid, C. Schlatter, The use of toxic equivalency factors in assessing occupational and environmental health risk associated with exposure to airborne mixtures of polycyclic aromatic hydrocarbons (PAHs), Chemosphere 32 (1996) 639-648.
[62] P.M. Gschwend, R.A. Hites, Fluxes of the polycyclic aromatic hydrocarbons to marine and lacustrine sediments in the northeastern United States, Geochim. Cosmochim. Acta 45 (1981) 2359-2367.

[63] N. Ohkouchi, K. Kawamura, H. Kawahata, Distributions of three- and seven rings polynuclear aromatic hydrocarbons on the deep sea floor in Central Pacific, Environ. Sci. Technol. 33 (1999) 3086-3090.

[64] M.B. Yunker, R.W. Macdonald, R.M. Vingarzan, H. Reginal, D. Goyette, S. Sylvestre, PAHs in the Fraser River basin: a critical appraisal of PAH ratios as indicators of PAH source and composition, Org. Geochem. 33 (2002) 489-515.

[65] M.R. Mannino, S. Orecchio, Polycyclic aromatic hydrocarbons (PAHs) in indoor dust matter of Palermo (Italy) area: extraction, GC-MS analysis, distribution and sources, Atmos. Environ. 42 (2008) 1801-1817.

[66] C.L. Potter, J.A. Glaser, L.W. Chang, J.R. Meier, A.D. Majid, R.F. Herrmann, Degradation of polynuclear aromatic hydrocarbons under bench-scale compost conditions, Environ. Sci. Technol. 33 (1999) 1717-1725.

[67] L.T. Taylor, D.M. Jones, Bioremediation of coal tar PAH in soils using biodiesel, Chemosphere 44 (2001) 1131-1136. 